IZA DP No. 5359

Sequentiality versus Simultaneity: Interrelated Factor Demand

Magne Krogstad Asphjell

Wilko Letterie

Øivind A. Nilsen

Gerard A. Pfann

December 2010 


\title{
Sequentiality versus Simultaneity: Interrelated Factor Demand
}

\author{
Magne Krogstad Asphjell \\ Norwegian School of Economics and Business Administration \\ Wilko Letterie \\ Maastricht University \\ Øivind A. Nilsen \\ Norwegian School of Economics and Business Administration \\ and IZA
}

\author{
Gerard A. Pfann \\ Maastricht University \\ and IZA
}

Discussion Paper No. 5359

December 2010

\author{
IZA \\ P.O. Box 7240 \\ 53072 Bonn \\ Germany \\ Phone: +49-228-3894-0 \\ Fax: +49-228-3894-180 \\ E-mail: iza@iza.org
}

Any opinions expressed here are those of the author(s) and not those of IZA. Research published in this series may include views on policy, but the institute itself takes no institutional policy positions.

The Institute for the Study of Labor (IZA) in Bonn is a local and virtual international research center and a place of communication between science, politics and business. IZA is an independent nonprofit organization supported by Deutsche Post Foundation. The center is associated with the University of Bonn and offers a stimulating research environment through its international network, workshops and conferences, data service, project support, research visits and doctoral program. IZA engages in (i) original and internationally competitive research in all fields of labor economics, (ii) development of policy concepts, and (iii) dissemination of research results and concepts to the interested public.

IZA Discussion Papers often represent preliminary work and are circulated to encourage discussion. Citation of such a paper should account for its provisional character. A revised version may be available directly from the author. 
IZA Discussion Paper No. 5359

December 2010

\begin{abstract}

\section{Sequentiality versus Simultaneity: Interrelated Factor Demand ${ }^{*}$}

A structural model is developed and estimated by a maximum likelihood routine to investigate interrelated factor demand subject to nonconvex adjustment costs. The dataset concerns Norwegian plants operating in manufacturing industries and it covers the period 1993-2005. The estimates indicate that it is advantageous to adjust the stock of labour and capital simultaneously. The cost advantage of simultaneous changes is small for capital but is large for labour. The empirical results suggest that when estimating separate factor demand models the bias of parameter estimates is most severe in case of labour demand.
\end{abstract}

JEL Classification: D92, E22, E24, J23, L60

Keywords: factor demand, labour, capital, interrelation, nonconvex adjustment costs

Corresponding author:

Øivind A. Nilsen

Norwegian School of Economics and Business Administration

Department of Economics

Hellevn. 30

NO-5045 Bergen

Norway

E-mail: oivind.nilsen@nhh.no

\footnotetext{
* We like to thank Russell Cooper, Dan Hamermesh and seminar participants at the Norwegian School of Economics and Business Administration, Maastricht University and the CAED/COST 2010 conference in London for providing constructive and valuable comments at various stages of the research project resulting in this paper. The usual disclaimer applies.
} 


\section{Introduction}

Firms have been observed to adjust the stock of their most productive factors, such as capital and labour, in a lumpy fashion. Thus, they tend to concentrate big changes into short periods while inaction dominates between these spikes. Such a pattern suggests that the smooth adjustment of the important input factors is precluded by nonconvex, for instance linear or fixed, costs leading to partial irreversibility of factor input decisions.

With a few exceptions, the existing literature on the irreversibility of production factors, has considered separate adjustment of one quasi-fixed production factor alone. ${ }^{1}$ However, Hamermesh (1993, p234-235) observes that one can only understand the dynamics of factor demand if one specifies a full model involving all inputs into production and if one allows for the possibility that each is quasi fixed. In fact, Abel and Eberly (1998) note that the observed lumpy employment pattern may not solely be caused by a fixed cost component of labour adjustment. They show that lumpy investment behaviour may cause simultaneous large employment adjustments in a model where labour demand is a fully flexible production factor. In line with this result Bloom (2009) finds that ignoring labour adjustment costs, as is typical in the investment literature, is a reasonable approximation when modelling investment, while a model with labour adjustment costs only, as is typical in the dynamic labour demand literature, is problematic in the sense that the estimated parameters are far away from the true ones found in a model that included both investment and labour adjustment costs. These results indicate that controlling for investment dynamics is important when analysing the more flexible labour input decisions.

Earlier research on multivariate factor input decisions suggests that the decisions about changing several input factors are mutually dependent. Interrelation was initially

\footnotetext{
${ }^{1}$ For capital adjustment, see recent studies by Abel and Eberly (2002), Cooper and Haltiwanger (2006), Letterie and Pfann (2007) and Nilsen and Schiantarelli (2003). For labour adjustment, see the seminal contribution by Hamermesh (1989), Pfann and Verspagen (1989), and the more recent ones of Abowd and Kramarz (2003), Rota (2004), and Nilsen et al. (2007).
} 
addressed using sector-level data in a linear setting by Nadiri and Rosen (1969). This study was not based on a structural model with adjustment costs but it inspired others to investigate the issue of interrelated factor demand decisions more deeply. Shapiro (1986) expands upon Nadiri and Rosen (1969) and estimates a structural dynamic model of factor demand with interrelation derived from the Euler equations. Galeotti and Schiantarelli (1991), and, more recently, Merz and Yashiv (2007), have studied the topic of interrelation in a framework without nonconvex costs of adjustment. Thus, from these findings it is hard to learn much about the source of the lumpiness often seen in micro data. There is a substantial amount of inaction observations for both labour and capital adjustments. This lumpiness may reflect the existence of nonconvexities in the adjustment costs of the input factors. Recent empirical studies based on micro data by Sakellaris (2004), Letterie et al. (2004), and Nilsen et al. (2009) have indeed revealed that in the context of lumpy adjustment the dynamics of labour and capital demand are interrelated. In particular, these papers have shown that at the micro level investment and labour spikes tend to occur simultaneously. This could result from complementarities in the production process. It may also stem from reduced adjustment costs when adjusting input factors at the same time, making a firm preferring simultaneous adjustment of factor demand decisions (i.e. simultaneity) to sequential changes in inputs (i.e. sequentiality).

Of course, the described pattern may also reflect the nature of shocks to the shadow values of the input factors. Furthermore, the studies by Sakellaris, Letterie et al., and Nilsen et al. are all using non-structural and explorative approaches to analyse interrelatedness. It is therefore hard to identify whether the simultaneity is due to the nature of the changes in the shadow values of the factors inputs, whether it is due to the production technology, or whether it is caused by interrelated adjustment costs. The advantage of a structural model is that one could potentially disentangle these three effects. Furthermore, it would also make it 
possible to identify whether lumpy investment behaviour for one input is the effect of fixed costs for this factor, or caused by interrelations in the adjustment cost function.

This paper serves three purposes. First, the consequences of interrelation are investigated theoretically by developing a structural model where adjustments of quasi-fixed input factors involve nonconvex costs. In addition to the nonconvex adjustment costs, the structural model incorporates interrelated adjustment costs that could either be negative (i.e. reduced costs due to simultaneity) or positive (making sequentiality less costly). The model deviates from work by Eberly and Van Mieghem (1997), Dixit (1997), Abel and Eberly (1998), and Bloom (2009) in the sense that it allows for the possibility that adjustment costs may decrease or increase when the firm decides to adjust two factors simultaneously. The occurrence of simultaneous adjustment depends on the interrelation and especially on the question whether or not interrelation adds to the costs of changing inputs or lowers those costs. One reason for the latter case, i.e. simultaneity of the two types of adjustments, is when simultaneous adjustment reduces the time of disruption to the production process. On the other hand, one could also think of a case where it would be efficient to implement input changes subsequently, making a firm preferring sequentiality. For instance, when introducing a new technology, it might be economically reasonable to hire and train new workers prior to investing, such that the new technology becomes productive as soon as possible after installation.

Secondly, estimates are obtained of the non-convex costs associated with adjusting labour and capital. The model is applied to investigate empirically the dynamics of joint labour and capital demand decisions. Using Norwegian plant level data covering the manufacturing sector from 1993-2005, estimates of the adjustment costs parameters of the model are obtained by employing a maximum likelihood routine. Thereby it is possible to assess whether simultaneous adjustment of labour and capital is beneficial or not. 
Thirdly, it is assessed whether neglecting interrelation in factor demand models implies omission bias in parameter estimates of separate factor demand models. The theoretical model is used to show under which conditions interrelation plays an important role in the input equations. By estimating both separate and interrelated factor demand models the implications in terms of omission bias are determined.

The paper proceeds as follows. In section 2 the theoretical model is developed. In section 3 the role of fixed costs in relation with the cost of interrelationship is discussed. The econometric model is described in section 4, while the data are described in section 5 . The empirical results are presented in section 6. Finally, section 7 concludes.

\section{The model}

Consider a firm that employs two production factors (capital $K_{t}$ and labour $L_{t}$ in year $t$ ) to produce a non-storable output. The firm's objective function is given by

$$
V_{t}=E_{t} \sum_{s=0}^{\infty} \beta^{s}\left[F\left(A_{t+s}, K_{t+s}, L_{t+s}\right)-w_{t+s} L_{t+s}-C\left(I_{t+s}, K_{t+s}, H_{t+s}, L_{t+s}\right)\right]
$$

The term $E_{t}$ indicates that expectations are taken with respect to information available at time t. The discount rate is given by $\beta$ with $0<\beta<1$. The variable $w_{t}$ denotes the wage paid by the firm to a full time worker. Capital and labour adjustment are denoted by $I_{t}$ and $H_{t}$

respectively. Production is given by the expression $F\left(A_{t}, K_{t}, L_{t}\right)$ where $A_{t}$ captures randomness in technology or stochastic behaviour of the demand conditions the firm is facing. When changing the stock of capital or the number of workers the firm incurs adjustment costs defined as: 


$$
\begin{aligned}
C\left(I_{t}, K_{t}, H_{t}, L_{t}\right) & =\left[p_{t}^{I} I_{t}+\alpha^{K} \cdot \mathrm{I}\left(I_{t} \neq 0\right)+\frac{b^{k}}{2}\left(\frac{I_{t}}{K_{t}}\right)^{2} \cdot K_{t}\right] \\
& +\left[p_{t}^{H} H_{t}+\alpha^{L} \cdot \mathrm{I}\left(H_{t} \neq 0\right)+\frac{b^{L}}{2}\left(\frac{H_{t}}{L_{t}}\right)^{2} \cdot L_{t}\right] \\
& +\alpha^{K L} \cdot \mathrm{I}\left(I_{t} \neq 0\right) \cdot \mathrm{I}\left(H_{t} \neq 0\right)
\end{aligned}
$$

In the adjustment cost function the indicator function I(.) takes the value 1 if the condition in brackets is satisfied and equals zero otherwise. The parameter $\alpha^{K L}$ is positive if a joint adjustment would increase the cost relative to a sequential solution. This is the case if more resources are spent on a joint adjustment because of more time spent on training or more disruptions to production compared to a sequential adjustment strategy. On the other hand, $\alpha^{K L}$ will be negative in cases where a simultaneous adjustment strategy will give the firm a relative cost advantage. A positive $\alpha^{K L}$ will, all other things equal, cause the number of sequential adjustments to increase, indicating a relatively low correlation in factor demands, while a negative $\alpha^{K L}$ will cause the number of simultaneous adjustments to increase, indicating a relatively high correlation in factor demands.

The specification allows for nonconvexity and the adjustment costs in this framework are recognized as a mix of different structures. The prices of the input factors are expressed as $p_{i t}^{I}$ and $p_{i t}^{H}$. These prices may include both the purchase price and linear adjustment costs. Fixed cost parameters are given by $\alpha^{K}$ and $\alpha^{L}$ and are assumed to be independent of whether the changes of levels of inputs are positive or negative. ${ }^{2}$

\footnotetext{
${ }^{2}$ This is just one way of modeling nonconvexity. Alternative adjustment cost specifications could account for loss of production while adjustment takes place for instance. One could also add various types of asymmetry in the adjustment cost parameters. For instance, the model could easily have been extended to allow the prices to be asymmetric such that the purchase price for a unit of capital is $p_{t}^{I^{+}}$, while the value of one unit of sold capital would be $p_{t}^{I-}$. Due to irreversibility of investment decisions these would then satisfy $p_{t}^{I^{+}}>p_{t}^{I^{-}}$. A parsimonious specification is chosen in this paper to facilitate estimation of the model.
} 
The firm decides upon the optimal size of the capital stock, $K_{t}$, by setting investment $I_{t}$ at the appropriate level, and correspondingly the amount of labour, $L_{t}$, by choosing the optimal level labour adjustment $H_{t}$. Capital and labour evolve according to the law of motion

$$
\begin{aligned}
& K_{i, t+1}=\left(1-\delta^{K}\right) K_{i, t}+I_{i, t} \\
& L_{i, t+1}=\left(1-\delta^{L}\right) L_{i, t}+H_{i, t}
\end{aligned}
$$

where $\delta^{K}$ measures the rate of capital depreciation, and $\delta^{L}$ measures the autonomous quit rate of workers. ${ }^{3}$ To obtain the optimal values for $I_{t}$ and $H_{t}$ equation (1) can be optimized with respect to these decision variables subject to the laws of motion governing the dynamics of capital and labour as given by equation (3). Before proceeding, note that the variables $\lambda_{t}^{K}$ and $\lambda_{t}^{L}$ are the conventional shadow values of an additional unit of capital and labour, respectively. Hence, they measure how the value of the firm changes if the constraints in equation (3) are relaxed or equivalently, if capital and labour are increased by one unit. It is easy to show that these represent the expected present discounted value of the marginal product of capital or labour minus the marginal adjustment costs in future periods. ${ }^{4}$ Using the shadow values $\lambda_{t}^{K}$ and $\lambda_{t}^{L}$ the first order conditions for capital and labour adjustment are

$$
\begin{aligned}
& \lambda_{t}^{K}-p_{t}^{I}-b^{K}\left(\frac{I_{t}}{K_{t}}\right)=0 \\
& \lambda_{t}^{L}-p_{t}^{H}-b^{L}\left(\frac{H_{t}}{L_{t}}\right)=0
\end{aligned}
$$

Similarly to Abel and Eberly $(1994,2002)$ the optimal factor demand adjustments are

$$
\begin{aligned}
& \frac{I_{t}}{K_{t}}=\left(\frac{\lambda_{t}^{K}-p_{t}^{I}}{b^{K}}\right) \\
& \frac{H_{t}}{L_{t}}=\left(\frac{\lambda_{t}^{L}-p_{t}^{H}}{b^{L}}\right)
\end{aligned}
$$

\footnotetext{
${ }^{3}$ It is assumed without any loss of generality that changes in capital and labour materialize with a lag. Furthermore, when estimating the model later in this paper only net workplace changes are observed.

${ }^{4} \mathrm{~A}$ derivation of the shadow values is provided in the appendix.
} 
Due to the presence of fixed costs of adjustment the firm will not always follow the decision rules presented in equation (5). Sometimes it may be optimal to abstain from adjusting capital and or adjusting labour. The threshold values for the shadow values $\lambda_{t}^{K}$ and $\lambda_{t}^{L}$ can be derived by finding the value for which a change in $I_{t}$ and or $H_{t}$ generates non-negative profits. The equation determining whether to change the stock of capital and or to adjust labour is

$$
\lambda_{t}^{K} I_{t}+\lambda_{t}^{L} H_{t} \geq C\left(I_{t}, K_{t}, H_{t}, L_{t}\right)
$$

The left hand side of (6) measures the expected benefits of changing capital and or labour, whereas the right hand side denotes the cost associated with the firm's decisions. ${ }^{5}$ Using equation (5) it can be shown that equation (6) holds if

$$
\begin{aligned}
& \frac{1}{2 b^{K}}\left(\lambda_{t}^{K}-p_{t}^{I}\right)^{2} K_{t} \cdot \mathrm{I}\left(I_{t} \neq 0\right)+\frac{1}{2 b^{L}}\left(\lambda_{t}^{L}-p_{t}^{H}\right)^{2} L_{t} \cdot \mathrm{I}\left(H_{t} \neq 0\right) \geq \\
& \alpha^{K} \cdot \mathrm{I}\left(I_{t} \neq 0\right)+\alpha^{L} \cdot \mathrm{I}\left(H_{t} \neq 0\right)+\alpha^{K L} \cdot \mathrm{I}\left(I_{t} \neq 0\right) \cdot \mathrm{I}\left(H_{t} \neq 0\right)
\end{aligned}
$$

To solve the optimization problem of the firm the conditions necessary for various adjustment decisions are derived.

\section{Factor input decisions}

The firm regards adjusting the stock of capital goods to be desirable if $\frac{1}{2 b^{K}}\left(\lambda_{t}^{K}-p_{t}^{I}\right)^{2} K_{t} \geq \alpha^{K}$. Labour adjustment is optimal if $\frac{1}{2 b^{L}}\left(\lambda_{t}^{L}-p_{t}^{H}\right)^{2} L_{t} \geq \alpha^{L}$. Necessary conditions for changing the amount of capital and labour are

$$
\left|\lambda_{t}^{K}-p_{t}^{I}\right|>\sqrt{\frac{2 b^{K} \alpha^{K}}{K_{t}}} \equiv A^{K}
$$

\footnotetext{
${ }^{5}$ The expression $\lambda_{t}^{K} I_{t}+\lambda_{t}^{L} H_{t}$ is an approximation of the benefits due to which it is possible to obtain a closed form solution. In a continuous time framework with one production factor a similar expression holds exactly.
} 


$$
\left|\lambda_{t}^{L}-p_{t}^{H}\right|>\sqrt{\frac{2 b^{L} \alpha^{L}}{L_{t}}} \equiv A^{L}
$$

Equation (8) shows that if the net benefits of adjusting capital and labour do not exceed a certain minimum threshold, the firm decides to abstain adjusting. These two thresholds are caused by the existence of the fixed adjustment costs $\alpha^{K}$ and $\alpha^{L}$.

Now consider the case where both necessary conditions to adjust capital and labour are satisfied as given in equation (8). Hence, the firm has an incentive to adjust at least one factor of production. However, due to the cost of interrelation the firm may need to select adjusting only one factor to maximise its objective function. It is optimal to adjust the number of workers rather than the stock of capital if $\frac{1}{2 b^{L}}\left(\lambda_{t}^{L}-p_{t}^{H}\right)^{2} L_{t}-\alpha^{L} \geq \frac{1}{2 b^{K}}\left(\lambda_{t}^{K}-p_{t}^{I}\right)^{2} K_{t}-\alpha^{K}$. Rearranging, and taking the square root, this inequality can be written as ${ }^{6}$

$$
\left|\lambda_{t}^{L}-p_{t}^{H}\right| \geq \sqrt{\frac{b^{L}}{b^{K}} \frac{K_{t}}{L_{t}}\left(\lambda_{t}^{K}-p_{t}^{I}\right)^{2}+\frac{2 b^{L}}{L_{t}}\left[\alpha^{L}-\alpha^{K}\right]}
$$

It is optimal to adjust an additional factor of production, i.e. both factors, if the net benefits associated with that adjustment exceed the fixed costs of that second input ( $\alpha^{K}$ or $\alpha^{L}$ ) plus the cost of interrelation $\alpha^{K L}>0$. Hence, it is worth also adjusting the stock of capital (given that adjusting labour yields a higher value of the firm if only one input needs to be selected) as soon as $\frac{1}{2 b^{K}}\left(\lambda_{t}^{K}-p_{t}^{I}\right)^{2} K_{t} \geq \alpha^{K}+\alpha^{K L}$. Similarly, labour will also be adjusted (given that changing capital yields a higher firm value if only one input is selected) as soon as

6 The term $\frac{2 b^{L}}{L_{t}} \alpha^{L}$ is positive given the assumptions about the adjustment costs parameters. Furthermore, $\frac{b^{L}}{b^{K}} \frac{K_{t}}{L_{t}}\left(\lambda_{t}^{K}-p_{t}^{I}\right)^{2}-\frac{2 b^{L}}{L_{t}} \alpha^{K}$ is also positive according to eq. (8). Thus, the sum of the two terms in the square brackets are positive. 
$\frac{1}{2 b^{L}}\left(\lambda_{t}^{L}-p_{t}^{H}\right)^{2} L_{t} \geq \alpha^{L}+\alpha^{K L}$. Hence, the boundaries determining when the firm will adjust both factors of production are

$$
\begin{aligned}
& \left|\lambda_{t}^{K}-p_{t}^{I}\right|>\sqrt{\frac{2 b^{K}\left(\alpha^{K}+\alpha^{K L}\right)}{K_{t}}} \equiv B^{K} \\
& \left|\lambda_{t}^{L}-p_{t}^{H}\right|>\sqrt{\frac{2 b^{L}\left(\alpha^{L}+\alpha^{K L}\right)}{L_{t}}} \equiv B^{L}
\end{aligned}
$$

As noted, demand for both factors is non-zero if the benefits of change (i.e. $\left|\lambda_{t}^{K}-p_{t}^{I}\right|$ and $\left.\left|\lambda_{t}^{L}-p_{t}^{H}\right|\right)$ are high. For instance, a high positive demand shock may increase the shadow values $\lambda_{t}^{K}$ and $\lambda_{t}^{L}$ simultaneously and hence provide the firm an incentive to expand the scale of the firm by increasing both factors of production. On the other hand, a firm may be increasing one input and decreasing the other input at the same time if shadow values move in opposite directions. Such a situation may arise due to a policy change affecting the relative price of the two factors of production or due to a technology shock changing the optimal share of the inputs to produce a certain level of output. But whether the adjustments of the input factors are made simultaneously or sequentially depends on the sign and size of the interrelated adjustment costs.

\section{3a. Adjustment decisions when $\alpha^{K L}>0$}

The analysis of firm level capital and labour demand decisions is summarized in figure $1 .^{7}$ The inaction area is bounded by $A^{K}$ and $A^{L}$ and $-A^{K}$ and $-A^{L}$. As already noted, this inaction is caused by the presence of the fixed adjustment costs, $\alpha^{K}$ and $\alpha^{L}$, meaning that the shadow value of a new unit of capital (labour) has to move beyond the thresholds defining area I. In

\footnotetext{
${ }^{7}$ Figures 1 and 2 deviate from the ones by Dixit (1997), Eberly and van Mieghem (1997), and Bloom (2009) in the sense that here the marginal value of an additional unit is on the axes, while the authors op. cit. have productivity $A$ normalized with $K$ and $L$, respectively.
} 
some cases marginal values for both factors exceed thresholds for sequential adjustment but not for joint adjustment. That is, cases where marginal values exceed threshold levels $A^{K}$ and $A^{L}$, but not $B^{K}$ and $B^{L}$. This situation can be represented by the points (i) and (ii) in Figure 1 , and there are four different areas where similar situations can arise. The firm only adjusts the two factors of production simultaneously in the area indicated by III. These areas move further away from the origin if $\alpha^{K L}$ increases which leads to a decrease of the area where simultaneous adjustment occurs. In fact, higher interrelated adjustment costs, $\alpha^{K L}$, increase the distance between $A^{K}$ and $B^{K}$, and between $A^{L}$ and $B^{L}$. This means that the net benefits of changes need to be significant before a firm chooses to change both input factors simultaneously.

\section{[Insert Figure 1 about here]}

To see the importance of the interrelated costs, it might be helpful to see what happens when the interrelated costs would be nonexistent, i.e. where $\alpha^{K L}=0 .^{8}$ That means that $A^{K}=B^{K}$, and $A^{L}=B^{L}$. In this case the areas where only one type of change would take place, area II, would become much smaller. The do-both-changes area III would at the same time be larger. Thus, the presence of positive interrelated costs would increase the area where a firm would only involve in one type of investment activity at the time. ${ }^{9}$ It is straightforward to show that the distance between the thresholds decreases as $\alpha^{i}$ increases:

\footnotetext{
${ }^{8}$ This is the case analysed by Dixit (1997).

${ }^{9}$ The curved boundary in the upper right corner in Figure 1 crosses the rectangular areas at $A^{L}=A^{K}$ and $B^{L}=B^{K}$. This curve, corresponding to the right hand side of equation (9), is concave if $\alpha^{K}>\alpha^{L}$ in the area where $\lambda_{t}^{K}-p_{t}^{I}>0$ and $\lambda_{t}^{L}-p_{t}^{H}>0$. Hence in Figure 1 the case $\alpha^{K}>\alpha^{L}$ is depicted where the curved boundary crosses the horizontal axis (i.e. where $\lambda_{t}^{L}-p_{t}^{H}=0$ ) at
} 


$$
\frac{\partial\left(B^{i}-A^{i}\right)}{\partial \alpha^{i}} \propto\left(\alpha^{i}+\alpha^{K L}\right)^{-1 / 2}-\left(\alpha^{i}\right)^{-1 / 2}<0
$$

and that $\lim _{\alpha^{i} \rightarrow \infty}\left(B^{i}-A^{i}\right)=0$ for $i \in\{K, L\}$. This means that in Figure 1 the area where the firm completely abstains adjusting, area I, and the area where both factors are adjusted simultaneously, area III, tend to move closer to each other as the fixed costs become larger relative to the interrelated cost, $\alpha^{K L}$. Thus, large fixed costs will suppress the importance of interrelation.

Omitting the interrelated costs when estimating a single factor demand model with adjustment costs may introduce a bias in the estimates of the fixed costs. Given a proxy for the shadow value of capital, when estimating a single factor $q$ model, the threshold will be located between $A^{K}$ and $B^{K}$ for investment, since it is the presence of zeroes that identifies the threshold. For labour demand the threshold will lie between $A^{L}$ and $B^{L}$ in a model considering labour only. This indicates that when interrelation is important then a single factor model is likely to produce biased and imprecise estimates for the adjustment costs in particular for a production factor with a low adjustment cost $\alpha^{i}$.

The analysis also shows that a lumpy adjustment pattern may be caused by the existence of interrelated adjustment costs, and not by fixed adjustment costs for the factor itself. Suppose for instance that $\alpha^{L}=0$ and that $\alpha^{K}>0$ and $\alpha^{K L}>0$. Note that if $\alpha^{L}=0$ then $A^{L}=0$. Though in this case labour does not involve fixed costs, the firm will not always

$x_{K} \equiv \sqrt{\frac{2 b^{K}\left(\alpha^{K}-\alpha^{L}\right)}{K_{t}}}$. If $\alpha^{K}<\alpha^{L}$ the right hand side of equation (9) is convex and the curved boundary crosses the vertical axis (i.e. where $\lambda_{t}^{K}-p_{t}^{I}=0$ ) at a point defined as $y_{L} \equiv \sqrt{\frac{2 b^{L}\left(\alpha^{L}-\alpha^{K}\right)}{L_{t}}}$. Note that if $\alpha^{K}=\alpha^{L}$, the boundary determining whether to invest or adjust labour becomes a straight line. The three other curves in the figure are analogous to the one just discussed. 
adjust labour when it invests (if $\left|\lambda_{t}^{K}-p_{t}^{I}\right|>A^{K} ;\left|\lambda_{t}^{L}-p_{t}^{H}\right|<B^{L}$ and both $\left|\lambda_{t}^{K}-p_{t}^{I}\right|$ and $\left|\lambda_{t}^{L}-p_{t}^{H}\right|$ are located at point (i) or (ii) in Figure 1 for instance). Hence, labour adjustment may appear intermittent with a large number of observations equal to zero even if it does not involve the firm incurring fixed costs for labour itself. Hamermesh (1993) and Abel and Eberly (1998) also argue that a variable factor can be subject to lumpy dynamics due to large adjustments of a less lumpy factor. They note that non convex adjustment costs of a lumpy factor translate into large adjustments of a more flexible factor because of complementarities. Similar findings are obtained by Dixit (1997) and Eberly and Van Mieghem (1997) who show that adjusting a less flexible factor always goes along with adjustment of a more flexible factor. However, a flexible factor may be adjusted on its own. These results indicate that adjustment costs of one factor have implications for the dynamics of other more flexible factors. The model developed above reveals that the cost of interrelation is an additional reason why more flexible factors like labour may exhibit intermittent patterns.

3b. Adjustment decisions when $\alpha^{K L} \leq 0$ (and still $\alpha^{K}>\alpha^{L}$ ).

If $\alpha^{K L} \leq 0$ firms actually benefit from adjusting both input factors simultaneously. The above analysis can be applied to a large extent here as well. The main difference is that the choice between capital or labour adjustment as presented below equation (9) has become irrelevant in this case. This is due to the fact that the thresholds $B^{L}$ and $B^{K}$ are smaller than $A^{L}$ and $A^{K}$ respectively if $\alpha^{K L} \leq 0$ (also see equations 8 and 10).

[Insert Figure 2 about here] 
Figure 2 indicates that if the firm incurs lower adjustment costs because of simultaneous adjustment area III where this event occurs becomes larger. If $\alpha^{K L}$ decreases then area III representing the situation that the firm changes both labour and capital moves in the direction of the origin of the figure. If $\alpha^{L}+\alpha^{K L} \leq 0$, the horizontal threshold at $B^{L}$ will lie at the horizontal axis of figure 2. This means if the firm invests it will also change its labour force, i.e. the area $I \neq 0, H=0$ disappears. If $\alpha^{K}+\alpha^{K L} \leq 0$ then the firm will always invest as soon as it alters its number of workers because the vertical threshold at $B^{K}$ will hit the vertical axis of the figure and the area $I=0, H \neq 0$ vanishes. If both conditions $\alpha^{K}+\alpha^{K L} \leq 0$ and $\alpha^{L}+\alpha^{K L} \leq 0$ hold then the firm will always change the two factors of production at the same time. Differently from figure 1, there are no areas where the firm must decide between investments in two adjustments that are separately profitable but not jointly.

Like in Section 3a the distance between the thresholds decreases for larger fixed costs:

$$
\frac{\partial\left(A^{i}-B^{i}\right)}{\partial \alpha^{i}} \propto\left(\alpha^{i}\right)^{-1 / 2}-\left(\alpha^{i}+\alpha^{K L}\right)^{-1 / 2}<0
$$

Furthermore $\lim _{\alpha^{i} \rightarrow \infty}\left(A^{i}-B^{i}\right)=0$ for $i \in\{K, L\}$. Again this implies that interrelation is less likely to be a main determinant for factors that involve large fixed adjustment costs. But single factor demand models for inputs with low fixed costs may be misspecified when interrelation is important.

\section{The econometric specification}

The adjustment decisions are dependent on the shadow values of capital and labour represented by $\lambda_{i t}^{K}$ and $\lambda_{i t}^{L}$ respectively. The econometrician will be able to observe firms' factor demand adjustments. However, marginal values $\lambda_{i t}^{L}$ and $\lambda_{i t}^{K}$ are not observable. Thus, 
in order to make the model estimable, these shadow values are approximated. For simplicity these are assumed to be linear functions of some variables captured by, $Z^{K}$ and $Z^{L}$. In addition stochastic error terms $\varepsilon_{i t}^{L}$ and $\varepsilon_{i t}^{K}$ are added to the definition of the shadow values to capture idiosyncratic factors. $^{10}$

$$
\begin{aligned}
& \lambda_{i t}^{K}-p_{i t}^{I}=\beta_{0}^{K}+\beta_{1}^{K} Z_{i t}^{K}+\varepsilon_{i t}^{K} \\
& \lambda_{i t}^{L}-p_{i t}^{H}=\beta_{0}^{L}+\beta_{1}^{L} Z_{i t}^{L}+\varepsilon_{i t}^{L}
\end{aligned}
$$

The stochastic terms $\varepsilon_{i t}^{K}$ and $\varepsilon_{i t}^{L}$ are bivariate normally distributed by assumption with zero means, variance $\sigma_{\varepsilon}^{K}$ and $\sigma_{\varepsilon}^{L}$, and correlation coefficient $\rho_{\varepsilon}$ :

$$
\left(\varepsilon_{i t}^{K}, \varepsilon_{i t}^{L} \mid\left(Z_{i t}^{K}, K_{i t}\right),\left(Z_{i t}^{L}, L_{i t}\right)\right) \sim N\left(\left(\begin{array}{l}
0 \\
0
\end{array}\right),\left(\begin{array}{cc}
\left(\sigma_{\varepsilon}^{K}\right)^{2} & \rho_{\varepsilon} \\
\rho_{\varepsilon} & \left(\sigma_{\varepsilon}^{L}\right)^{2}
\end{array}\right)\right)
$$

The vectors $Z^{K}$ and $Z^{L}$ contain sector and time dummies. Time dummies are used to capture the dynamics of factor input prices. In principle information on investment prices is available, but a proper variable to measure labour adjustment prices is absent. To capture both, time dummies are employed. Note that due to multicollinearity both the investment price and the time dummies cannot be used. Furthermore, $Z^{K}$ and $Z^{L}$ include information on the sales to capital ratio, $Y / K$, the sales to labour ratio, $Y / L$, and the wage rate, $w$. These variables are commonly used to proxy for fundamentals driving capital or labour demand. Here, the shadow value of capital $\lambda_{t}^{K}$ is also a function of $Y / L$ and $w$. In single factor models it is usually assumed that this is not the case. This is motivated by results due to Gilchrist and Himmelberg (1998) who show that marginal $q$ is a linear function of marginal productivity (i.e. the sales to capital ratio for investment) under imperfect competition and a CobbDouglas production technology if the marginal productivity is generated by a simple AR(1)

\footnotetext{
${ }^{10}$ It should be noted that this will also introduce error terms in the two demand equations, equations
} (5). 
process. However, from the expressions depicted in the appendix it can be observed that $\lambda_{t}^{K}$ is affected by expectations of future realizations of the labour decision. Hence, $\lambda_{t}^{K}$ is a function of expectations on future outcomes of $\lambda_{t}^{L}$. As a consequence, $Y / L$ and $w$ are included in $\lambda_{t}^{K}$ as well. Here, $\lambda_{t}^{L}$ is a function of $Y / L, w$ and $Y / K$ as well. A similar argument as above holds for why $Y / K$ affects $\lambda_{t}^{L}$. The proxies for the shadow value of labour and capital are admittedly approximations as the true shadow values $\lambda_{t}^{K}$ and $\lambda_{t}^{L}$ are complicated functions of future marginal productivity, future adjustment probabilities and future adjustment costs. Furthermore, in line with Nilsen and Schiantarelli (2003) and Letterie and Pfann (2007) in the estimations lagged values of the variables $Y / K, Y / L$ and $w$ are used for two reasons. First, it is easier for the firm's management to observe lagged rather than contemporaneous information. Secondly, another advantage is that lagging these variables reduces problems due to endogeneity.

Thus, with the approximation described in equation (13), and the threshold equations (8) and (10), all the necessary information is available to build up a bivariate probit model. That is, the problem is simplified by saying that every firm decides between three options per input factor in period $t$; no change, decrease, or increase. This gives in total nine factor adjustment regimes. The fact that each observation is assigned to one of the regimes, based on the values of $I / K$ and $H / L$ makes identification of the parameters of interest possible. Specifically, it is possible to estimate two different sets of threshold levels for separate and joint adjustments because different thresholds apply conditional on the adjustments being made sequentially or simultaneously. ${ }^{11}$

${ }^{11}$ Graphically, this means that observations are required such as that represented by point (i) in Figure 1. 
In the situation where it is optimal to adjust only one input factor, even though both exceed their thresholds $A^{K}$ and $A^{L}$, we may substitute approximations as given by (13) for $\lambda_{i t}^{K}-p_{i t}^{I}$ and $\lambda_{i t}^{L}-p_{i t}^{H}$ in equation (9). Thus, the firm will invest in labour rather than capital if

$$
\varepsilon_{i t}^{L} \geq \sqrt{\frac{b_{L}}{b_{K}} \frac{K_{i t}}{L_{i t}}\left(\left(\beta_{0}^{K}+\beta_{1}^{K} Z_{i t}^{K}\right)+\varepsilon_{i t}^{K}\right)^{2}+\frac{2 b_{L}}{L_{i t}}\left[\alpha^{L}-\alpha^{K}\right]}-\left(\beta_{0}^{L}+\beta_{1}^{L} Z_{i t}^{L}\right)
$$

Because the error terms $\varepsilon_{i t}^{L}$ and $\varepsilon_{i t}^{K}$ both enter in this inequality, the decision rule to be implemented in a likelihood function would introduce significant complexity. Therefore, to simplify it is assumed that the four curved lines in Figure 1 can be approximated by straight lines. $^{12}$

When the interrelated adjustment costs turn out to make simultaneous adjustment cost-efficient, i.e. $\alpha^{K L}<0$, the limits of the investment regimes become somewhat different. Because of the difference between cases with positive and negative interrelation costs represented by Figure 1 and 2, it is not possible to apply the same likelihood function in both cases. This makes it necessary to specify different likelihood functions conditional on the sign of $\alpha^{K L}$. The main structure of the function though, is identical.

The likelihood function to be used in the ML estimation follows a standard setup for discrete variables. ${ }^{13}$ It can be written as a sum of 9 different probability expressions for the nine different regimes summarized over periods $t$ and firms $i$. The probabilities are given by the standard cumulative bivariate normal distribution function. The expression below is an abbreviated version of the full log likelihood

\footnotetext{
${ }^{12}$ When probabilities are assigned to observations, the integrals of the four areas are calculated where the decision rule should be applied, and due to the approximation by a straight line the integrals are divided by two. Each part is then assigned to the appropriate action space. Thus, it is possible to write the likelihood using only values of the univariate and bivariate cumulative normal distribution functions.

${ }^{13}$ The choice for this model is based on reasons of computational simplicity. Admittedly, one could have developed a model to use more information from the data, as in a Tobit-type model. Regardless, the chosen model identifies the parameters of interest, so that there would only be efficiency gains from the alternative approach.
} 
$\log L=\sum_{t=1}^{T} \sum_{i \in \Omega_{t}^{+,-}} \log \Phi_{2}\left[-\sqrt{\frac{2 b^{K}\left(\alpha^{K}+\alpha^{K L}\right)}{K_{i t}}}-\beta_{0}^{K}-\beta_{1}^{K} Z_{i t}^{K},-\sqrt{\frac{2 b^{L}\left(\alpha^{L}+\alpha^{K L}\right)}{L_{i t}}}-\beta_{0}^{L}-\beta_{1}^{L} Z_{i t}^{L}, \rho_{\varepsilon}\right]$ $+\sum_{t=1}^{T} \sum_{i \in \Omega_{t}^{-, 0}} \log ()+.\sum_{t=1}^{T} \sum_{i \in \Omega_{t}^{-,+}} \log ()+.\ldots+\sum_{t=1}^{T} \sum_{i \in \Omega_{t}^{+,+}} \log ($.

$\Phi_{2}$ denotes the standard cumulative bivariate normal distribution function. $\Omega_{t}^{-,-}, \Omega_{t}^{-, 0}, \Omega_{t}^{-,+}, \ldots, \Omega_{t}^{+,+}$denote the sets of firms that in period $t$ are allocated in the different investment regimes. ${ }^{14}$ By maximizing the likelihood function the location of the thresholds $A^{K}, B^{K}, A^{L}$ and $B^{L}$ as defined in equations (8) and (10) is identified. The model allows to recover normalized estimates of $\quad \beta_{0}^{K}, \beta_{1}^{K}, \beta_{0}^{L}, \beta_{1}^{L}$, pseudo-thresholds $\sqrt{b^{K} \alpha^{K}}, \sqrt{b^{L} \alpha^{L}}, \sqrt{b^{K}\left(\alpha^{K}+\alpha^{K L}\right)}$ and $\sqrt{b^{L}\left(\alpha^{L}+\alpha^{K L}\right)}$ in addition to an estimated correlation coefficient, $\rho_{\varepsilon} \cdot{ }^{15}$ As in standard models of discrete outcomes, the ratio between the original parameter and standard deviations $\sigma_{\varepsilon}^{K}$ and $\sigma_{\varepsilon}^{L}$ is estimated. These ratios are referred to as normalized parameters. In other words it is not possible to identify convex and nonconvex cost parameters directly. However, using estimates of the normalized pseudothresholds facilitates identifying ratios of fixed cost parameters. If estimates of the parameters are recovered then the squared and normalized pseudo thresholds can be calculated

$$
\tilde{A}^{K} \equiv \frac{b^{K} \alpha^{K}}{\left(\sigma_{\varepsilon}^{K}\right)^{2}}, \tilde{A}^{L} \equiv \frac{b^{L} \alpha^{L}}{\left(\sigma_{\varepsilon}^{L}\right)^{2}}, \widetilde{B}^{K} \equiv \frac{b^{K}\left(\alpha^{K}+\alpha^{K L}\right)}{\left(\sigma_{\varepsilon}^{K}\right)^{2}} \text { and } \widetilde{B}^{L} \equiv \frac{b^{L}\left(\alpha^{L}+\alpha^{K L}\right)}{\left(\sigma_{\varepsilon}^{L}\right)^{2}}
$$

\footnotetext{
${ }^{14}$ Superscripts -, 0 or + denote negative, zero and positive adjustments of capital and labour, respectively. I.e. $\Omega_{t}^{-,-}$is the set of observations with negative adjustment of both factors in period $t$, $\Omega_{t}^{-, 0}$ is the set of observations with negative adjustment of capital and zero adjustment of labour, etc. ${ }^{15}$ These are called pseudo thresholds, since the estimates do not include the terms $\sqrt{2 / K_{i t}}$ and $\sqrt{2 / L_{i t}}$, while the thresholds $A^{K}, B^{K}, A^{L}$, and $B^{L}$ do.
} 
Because of the differences between the thresholds for separate and joint adjustments, the ratios between fixed cost parameters are:

$$
\begin{aligned}
& \frac{\tilde{B}^{K}-\tilde{A}^{K}}{\tilde{A}^{K}}=\frac{b^{K}\left(\alpha^{K}+\alpha^{K L}\right)-b^{K} \alpha^{K}}{b^{K} \alpha^{K}} \cdot \frac{\left(\sigma_{\varepsilon}^{K}\right)^{2}}{\left(\sigma_{\varepsilon}^{K}\right)^{2}}=\frac{\alpha^{K L}}{\alpha^{K}} \\
& \frac{\widetilde{B}^{L}-\tilde{A}^{L}}{\tilde{A}^{L}}=\frac{b^{L}\left(\alpha^{L}+\alpha^{K L}\right)-b^{L} \alpha^{L}}{b^{L} \alpha^{L}} \cdot \frac{\left(\sigma_{\varepsilon}^{L}\right)^{2}}{\left(\sigma_{\varepsilon}^{L}\right)^{2}}=\frac{\alpha^{K L}}{\alpha^{L}} \\
& \frac{\widetilde{B}^{K}-\tilde{A}^{K}}{\widetilde{B}^{L}-\tilde{A}^{L}} \cdot \frac{\tilde{A}^{L}}{\tilde{A}^{K}}=\frac{\alpha^{L}}{\alpha^{K}} \cdot \frac{\alpha^{K L}}{\alpha^{K L}}=\frac{\alpha^{L}}{\alpha^{K}}
\end{aligned}
$$

The ratio of convex cost parameters will only be identified as a normalized ratio as given below.

$$
\frac{\widetilde{B}^{K}-\tilde{A}^{K}}{\widetilde{B}^{L}-\tilde{A}^{L}}=\frac{b^{L}\left(\alpha^{L}+\alpha^{K L}\right)-b^{L} \alpha^{L}}{b^{K}\left(\alpha^{K}+\alpha^{K L}\right)-b^{K} \alpha^{K}} \cdot \frac{\left(\sigma_{\varepsilon}^{K}\right)^{2}}{\left(\sigma_{\varepsilon}^{L}\right)^{2}}=\frac{b^{L}}{b^{K}} \cdot \frac{\left(\sigma_{\varepsilon}^{K}\right)^{2}}{\left(\sigma_{\varepsilon}^{L}\right)^{2}}
$$

Since one can derive these ratios after estimation of pseudo-thresholds, it is also possible to estimate ratios of cost parameters directly as parameters in the likelihood function by changing the parameterization. Due to this the standard errors of the ratios depicted in equations (18)-(21) can be obtained. A step-wise procedure is chosen when carrying out estimations. In the first step, two different likelihood functions are applied, and two different sets of estimates are obtained. One conditional on a positive interrelation cost parameter $\alpha^{K L}$, and one assuming that $\alpha^{K L}<0$. By reviewing the estimates of pseudo thresholds and comparing $\tilde{A}^{K}$ with $\widetilde{B}^{K}$ and $\widetilde{A}^{L}$ with $\widetilde{B}^{L}$, one gets an indication of the sign of $\alpha^{K L}$, and thus which is the appropriate likelihood function to apply. In the second step, after changing the 
parameterization, the applicable likelihood function is used to obtain direct estimates of parameter ratios in equations $(18)-(21){ }^{16}$

\section{Data}

\section{5a. Sample construction}

The empirical evidence in this work is based on plant level information from Norway for plants in the manufacturing industry, covering the period 1993-2005. The data are collected by Statistics Norway. Focusing on manufacturing gives access to detailed information about production and production costs, together with detailed information about investment and employment. Attention is restricted to plants with 10 or more employees. Some data might be available for also smaller plants. Note however, that these observations may be associated with measurement errors since some of the information from these types of plants often are imputed by Statistics Norway. For the purpose of this paper it should not be critical, rather on the contrary. For these smaller plants it would be very hard to disentangle the effects of indivisibility from the effects caused by nonconvex adjustment costs. All auxiliary units which do not take part directly in production are excluded, such as separate storage and office units. Plants in which the central or local governments own more than $50 \%$ of the equity have also been excluded from the sample, as well as observations that are reported as "copied from previous year”. This actually means that a data entry is missing. The remaining data were trimmed to remove outliers. ${ }^{17}$ Finally, only plants for which 6 or more consecutive observations are available are included. The first 5 periods for each plant are used to proxy the initial stock of capital as explained in the appendix. The final sample used in the

\footnotetext{
${ }^{16}$ Asphjell, Nilsen and Letterie (2010) investigate whether the maximum likelihood routine employed in this paper is capable of retrieving the true parameters from a simulated dataset. All simulations indicate the routine has satisfactory properties when the data set has the size of the data used for the estimations in this paper.

${ }^{17}$ Observations where the investment rate, $I / K$, the net workplace changes $(H / L)$, and wage per employee, $w$, were outside "reasonable" limits are excluded.
} 
maximum likelihood estimations include 2460 plants with a total of 13511 observations from the period 1998-2005. ${ }^{18}$ The final sample is considerably smaller than the original sample. However, even though a lot of observations are excluded on account of the restrictions applied, the sample includes about $50 \%$ of workers employed in the Norwegian industry sector. ${ }^{19}$ Also, compared to the original data, in the final sample the different industry sectors are represented by a proportional number of observations.

Investment is defined as purchases minus sales of fixed capital. Expenditures related to repairs of existing capital goods are excluded from the definition of investment. In the analysis equipment includes machinery, office furniture, fittings and fixtures, and other transport equipment, excluding cars and trucks. Employment, $L_{\mathrm{t}}$, is measured as number of employees, measured as an average over five selected months (Feb., Apr, June, Sept., and Nov.). ${ }^{20}$ The wage rate, $w$, is defined as total wage expenses including pay-roll taxes divided by the number of employees (1000 NOK in 1996 prices). Output, $Y_{\mathrm{t}}$, is defined as the value of gross production, measured as sales of own produced goods corrected for inventory changes (1000 NOK in 1996 prices). Capital stock was built up using the perpetual inventory formula, using information about initial capital stock and net investments (see the data appendix for details about the initial capital stock). ${ }^{21,22}$

\footnotetext{
${ }^{18}$ The criterion that these plants are only included if they have at least six or more useable observations, might introduce some selection issues. Probably larger and more successful plants are more likely to be present in the data.

${ }^{19}$ The loss of observations is to a large extent caused by our two restrictions (i) number of employees greater or equal to 10, and (ii) at least 6 consecutive observations.

${ }^{20}$ In the manufacturing industry most workers (92 percent) are working full time in the sample period. As a result, employment changes capture well the fluctuations of the labor input.

${ }^{21}$ Nominal values are deflated using a producer price index.

${ }^{22}$ In this paper yearly data are used. By looking at year-to-year changes in levels the gross costs of adjustment are ignored.
} 


\section{5b. Descriptives}

Table 1 presents a number of summary statistics. The average firm in the sample employs approximately 75 individuals, $L$. In 1996 prices the average stock of capital, $K$, is about 60 million NOK or $€ 7.5$ million. This reflects that in manufacturing industries firms are relatively capital intensive.

[Insert Table 1 about here]

Table 2 reports the frequency distribution of the labour adjustment rates. Observe that labour adjustment is zero in 11.2 percent of the cases, supporting the notion that non convex costs play a role in determining labour adjustments. A similar argument can be put forward for capital adjustment for which 15.1 percent zeroes are reported. At least one adjustment is being made very often as both capital and labour adjustment are zero at the same time in only 2.2 percent of the observations. Just one adjustment is made (capital or labour adjustment is non zero) in 21.9 percent of the cases. For sequential adjustment a necessary condition is that in a period only one adjustment must take place. Hence, this finding is suggestive of the advantage of simultaneous adjustment. In fact the data indicate that 75.9 percent of the observations are cases where firms adjust labour and capital simultaneously.

[Insert Table 2 about here]

Table 3 reports the correlations between contemporaneous, lagged and forwarded investment and hiring rates. It appears that contemporaneous hiring rates and their lagged and forwarded counterparts are negatively correlated at -0.08 (-0.083 and -0.078 in the table). This indicates that few labour adjustments occur in two consecutive years. Contemporaneous investment is 
positively correlated with lagged and forwarded investment rates with a coefficient of 0.148 and 0.131 respectively. This means that large investments are spread over at least two consecutive years. The correlation coefficient between contemporaneous capital and labour adjustment rates is about 0.116 . In line with cost advantages of simultaneous adjustment of labour and capital Table 3 indicates that the correlation of contemporaneous labour (capital) adjustment rates with lagged or forwarded capital (labour) adjustment rates is lower, namely 0.08 (ranging between 0.070 and 0.090).

[Insert Table 3 about here]

\section{Results}

The descriptive statistics so far indicate that firms in the sample tend to implement labour and capital adjustments simultaneously. To get a better understanding of what drives the simultaneity of labour demand and investment the structural model is estimated to identify whether interrelations in the adjustment cost function are causing this phenomenon.

Table 4 presents the estimation results. ${ }^{23}$ The thresholds satisfy: $A^{K} \approx B^{K}$ and $A^{L}>B^{L}$. This result is consistent with the notion that $\alpha^{K L}<0$. Thus firms have an incentive to adjust both input factors simultaneously. Note that since the model allows for both correlation in the demand shock, and that the input factors may be complementary in the production process, negative interrelated adjustment costs are likely to be the driving force for the simultaneous input factor adjustments in our data. When taking a look at the interrelated costs relative to the fixed component of the adjustment costs for capital and

\footnotetext{
${ }^{23}$ The model was first estimated employing the maximum likelihood routine using the assumption that simultaneous adjustment is costly: $\alpha^{K L}>0$. The estimates of this analysis indicate that the assumption $\alpha^{K L}>0$ does not hold. The results show that the estimated thresholds are consistent with cost advantages of simultaneous adjustment of labour and capital. These results are not reported to save some space.
} 
labour it is found that interrelation is far more important for labour than for capital. In fact the results imply that $\frac{\alpha^{K L}}{\alpha^{L}} \approx-0.30$ and that $\frac{\alpha^{K L}}{\alpha^{K}} \approx 0$. As pointed out in Section 3 , this means that if a firm invests it is inclined to change its number of workers at the same time. In Dixit (1997), Eberly and Van Mieghem (1997) and Abel and Eberly (1998) the firm has an incentive to conduct joint adjustment because of complementarities in the production function. The findings presented here suggest that joint adjustment is favourable because of cost advantages.

[Insert Table 4 about here]

A number of robustness checks of the results have been done. In Table 4 it is assumed that the information set of firms includes period $t-1$ variables and that these variables are generated by a simple AR(1) process. Hence, estimates are reported based on lagged capital productivity $(Y / K)$, lagged labour productivity $(Y / L)$ and the lagged wage rate $(w)$. The first robustness check is where the model is estimated by increasing the number of lags of $Y / K$, $Y / L$ and $w$ such that the information set of the firm is based on period $t-1$ and period $t-2$ variables, based on the assumption that the variables are generated by an $\mathrm{AR}(2)$ process. Secondly, the model is estimated including linear and squared terms of $Y / K, Y / L$ and $w$. The reason for this is that using marginal productivity variables to proxy for the shadow values is most suitable when assuming a Cobb-Douglas production technology (Gilchrist and Himmelberg, 1998). However, this production function is rather restrictive when it comes to substitutability of production factors. Therefore, the model is estimated using a more flexible function. Finally, to capture micro level heterogeneity the three types of models just described are estimated again in the spirit of Mundlak (1978), Chamberlain (1984) and Hu and Schiantarelli (1998) by including presample means of $Y / K, Y / L$ and $w$ in the proxy for the 
shadow value of capital and labour (also see equation 14). ${ }^{24}$ These means are calculated using the first 5 observations available for a plant that are used to calculate the initial stock of capital as explained in the appendix. These observations are not used for estimation of the model. All these checks reveal that the estimates of the adjustment cost ratios and the thresholds are robust to the assumptions made concerning the specification of the shadow values of labour and capital. ${ }^{25}$ Because all estimates tell the same story only the results based on proxying shadow values with once lagged, i.e. $t-1$, and linear terms of $Y / K, Y / L$ and $w$ employing presample means to capture micro level heterogeneity are depicted in Table 5.

[Insert Table 5 about here]

One concern is that it would be difficult to identify what is caused by positively correlated demand shocks and what is caused by negative interrelated adjustment costs. Both may induce synchronized factor adjustments. First, note however, that in 38.6 percent of the observations capital and labour are adjusted in the same direction, whereas these inputs move in opposite direction in 37.3 percent of the cases. The former is consistent with demand fluctuations, while the latter is consistent with technological changes affecting the composition of input factors. The fact of such a significant share of the observations where inputs move in opposite direction facilitates disentangling whether adjustment dynamics are due to interrelated adjustment costs, demand or technology shocks. Secondly, in principle the maximum likelihood routine allows for the possibility of demand shocks due to the presence

\footnotetext{
${ }^{24}$ The statistical approach employed in this paper cannot control for firm specific components by using fixed or random effects. It is impossible to integrate out fixed effects in the highly non-linear model developed in this paper. Assuming random effects would complicate the likelihood function and make it intractable.

${ }^{25}$ The hypothesis that the parameters of the variables proxying for the shadow variable of capital are jointly significant cannot be rejected employing an $F$-test, except for the case where the shadow value includes $t-1$ and $t-2$ information together with presample means. The parameters of the variables proxying for the shadow value of labour are always jointly significant.
} 
of the correlation coefficient $\rho_{\varepsilon}$ of the shocks $\varepsilon_{i t}^{L}$ and $\varepsilon_{i t}^{K}$ to the marginal value of labour and capital. The estimates reveal that $\rho_{\varepsilon} \approx 0.15$. This means that shocks to the fundamental variables driving labour and capital demand tend to move in the same direction. A precise interpretation of the shocks is cumbersome, however, as they are picking up misspecification of the model, technology shocks, or other shocks unaccounted for by the model. Thirdly, Asphjell, et al. (2010) have tested the ability of the maximum likelihood routine to recover the adjustment cost ratios and $\rho_{\varepsilon}$ from simulated datasets. From these experiments it appears that the estimation routine is capable of retrieving $\rho_{\varepsilon}$ from the data very precisely. Also, in all models estimated for the robustness checks it is found that the estimate of $\rho_{\varepsilon}$ is very stable. This indicates that the estimation procedure is very good in sorting out whether simultaneity is due to demand shocks or interrelated adjustment costs.

As pointed out in Section 3, when interrelation is important then a single factor model is likely to produce biased estimates for the adjustment costs. Table 6 displays parameter estimates after two separate estimations for capital and labour. Using a separate estimation strategy, it is possible to recover one threshold estimate per factor, but it is impossible to estimate the correlation coefficient, $\rho_{\varepsilon}$, of the error terms in the two equations. The estimated threshold for capital has hardly changed (359.7 and 357.1, Table 4 and Table 6 respectively). However, the estimated threshold for labour, 0.537, lies somewhere in between the two estimates of $A^{L}$ and $B^{L}$ reported in Table 4, i.e. 27 percentage points lower than the $A^{L}$ reported in Table 4 (but admittedly 5 percentage points higher than the reported $B^{L}$ in the same table). It appears that the single demand model for labour identifies quite closely the threshold $B^{L}$ of Table 4 (also see equation 10) which is determined by the fixed $\operatorname{cost} \alpha^{L}>0$ and the cost of interrelation $\alpha^{K L}<0$. Hence, if one would base an adjustment cost estimate for labour on the single demand model it is likely to reflect the cost of interrelation $\alpha^{K L}$ as well. Using the data of this paper it means that a researcher will obtain an 
underestimate of the true value of the adjustment cost parameter $\alpha^{L}$. What these results help to illustrate is that ignoring the interrelated relationship between the demand for labour and capital does not really matter for the estimated adjustment threshold for capital, the factor with the highest fixed cost of adjustment. In other words, the mistake made by ignoring simultaneity is largest for labour. This is in line with the theoretical finding previously stated in Section 3, which is that when interrelation is important, a single factor model is likely to produce biased estimates for the adjustment costs in particular for a production factor with a low fixed adjustment cost $\alpha^{i}$. Bloom (2009) also states that ignoring labour demand when investigating investment is not very harmful. However, when estimating a demand model for labour, ignoring capital adjustment yields biased estimates.

\section{[Insert Table 6 about here]}

From the joint estimates it is also possible to come up with some simple calculations to figure out whether the convex costs for capital are larger than the ones for labour, or vice versa. As a starting point it may be useful to point out that the results presented in Table 4 indicate that the fixed costs of capital are much larger than those of labour. However, when it comes to the frequencies of zero adjustments relatively similar patterns are observed for capital and labour. These two facts can be consistent with optimal behaviour in the model if marginal values of capital in general are a lot larger in absolute size, i.e. if $\sigma^{K}$ is a lot larger than $\sigma^{L}$. To investigate the relative size of the convex costs, a simple numerical simulation exercise is conducted. As reported in Table 4, the convex cost ratio is found to be $\frac{b_{L}}{b_{K}} \cdot \frac{\left(\sigma_{\varepsilon}^{K}\right)^{2}}{\left(\sigma_{\varepsilon}^{L}\right)^{2}}=10.16$. With this estimate at hand, together with other parameter estimates of the model, the possible combinations of $b^{L} / b^{K}$ and $\sigma^{K} / \sigma^{L}$ are investigated. From a 
simulation it is found that a convex cost parameter ratio $b^{L} / b^{K}=0.29$ and a ratio of standard deviations $\sigma^{K} / \sigma^{L}=5.9$ fit the data best concerning key moments like inaction shares and first and second moments of adjustments. ${ }^{26}$ These findings indicate that marginal convex adjustment costs and the variation in shadow values are largest for capital.

The results obtained from the simulation can also be employed to assess the size of convex costs relative to the nonconvex cost. In terms of the actual costs incurred by the firms, the size of the convex cost component depends on the actual size of adjustment and the current level of the input, as opposed to the fixed cost component, which is simply fixed over adjustment and firm size. To illustrate how the importance of convex versus fixed costs varies across firms and adjustment strategies, consider Figures 3 and 4, where the curves represent combinations where the sizes of convex and fixed costs are equal. For both factors, the figures show that for medium and large sizes of inputs and adjustment rates, the convex component dominates over the purely fixed costs, while fixed costs play an important role for smaller adjustments, and especially so for hiring and firing decisions. Conditional that adjustment takes place, at sample medians of adjustments and input levels, fixed costs are about 0.15 times the size of convex costs for both separate capital adjustments and separate labour adjustments, while the same ratio is about 0.1 for labour adjustments that are conducted jointly with capital investments. Although these numbers may seem small, one should not conclude from this that fixed costs are not economically important to the firms in the sample. The impact on those firms that abstain from adjustments due to the presence of fixed costs is substantial as can be seen from the number of zeroes in the data.

[Insert Figures 3 and 4 about here]

${ }^{26}$ For a description of the simulation see the appendix. 


\section{Conclusion}

This paper presents a structural model describing the joint determination of labour and capital adjustment by a firm. According to the model a firm has an incentive to adjust input factors sequentially, if it is costly to adjust two factors of production at the same time. On the contrary, the firm is inclined to adjust simultaneously if there are cost advantages of doing so. Another prediction from the theoretical model is that when fixed costs of the inputs differ substantially, in a model neglecting interrelated costs serious omission bias will occur in the estimated adjustment costs for the production factor with the lower lumpy costs.

Norwegian plant level data concerning the manufacturing industry in the period 19932005 are used to estimate the structural parameters of the model. The maximum likelihood routine reveals that simultaneous adjustment of the two production factors yields cost advantages. The cost advantage is small for capital but is large for labour. The estimation takes care of different possibilities for the production technology. Furthermore, the estimation routine explicitly accounts for demand shocks. Hence, the simultaneity finding is neither due to a specific choice for the production technology implying that a firm actually has to have more of the two factors because they are complementary nor is the finding solely due to demand shocks driving input factors into the same direction. So, also interrelated adjustment costs imply the simultaneity of factor demand decisions. The estimates indicate that the fixed cost of adjusting capital is large compared to the fixed cost of adjusting labour. The empirical results imply that when estimating separate factor demand models the adjustment cost parameters are biased most severely in case of labour demand. 


\section{References}

Abel, A.B., and Eberly, J.C., 1994, “A Unified Model of Investment Under Uncertainty”, American Economic Review, 84, 1369-1384.

Abel, A.B., and Eberly, J.C., 1998, “The Mix and Scale of Factors with Irreversibility and Fixed Costs of Investment”. Carnegie-Rochester Conference Series on Public Policy, 48, 101-135.

Abel, A.B., and Eberly, J.C., 2002, “Investment and Q with Fixed Costs: An Empirical Analysis.” Mimeo, The Wharton School, University of Pennsylvania.

Abowd, J.M. and Kramarz, F., 2003, “The Costs of Hiring and Separations”, Labour Economics, 10, 499-530.

Asphjell, M.K., Ø.A. Nilsen, and W. Letterie, 2010, "Estimating Interrelated Nonconvex Adjustment Costs by Maximum Likelihood.” Mimeo, Norwegian School of Economics and Business Administration

Bloom, N., 2009, “The Impact of Uncertainty Shocks”, Econometrica, 77, 623-685.

Chamberlain, G., 1984, “Panel Data.” In Griliches, Z., Intriligator, M. (Eds.), Handbook of Econometrics, vol. II. North Holland, Amsterdam, 1247-1318.

Cooper, R.W. and Haltiwanger J.C., 2006, “On the Nature of Capital Adjustment Costs”, Review of Economic Studies, 73, 611-633

Dixit, A., 1997, “Investment and Employment Dynamics in the Short and the Long Run”, Oxford Economic Papers, 49, 1-20.

Dixit, A., and R. Pindyck, 1994, Investment under Uncertainty, Princeton University Press, Princeton, New Jersey.

Eberly, J.C., van Mieghem, J.A., 1997, “Multi-Factor Dynamic Investment Under Uncertainty”, Journal of Economic Theory, 75, 345-387. 
Galeotti, M. and Schiantarelli, F., 1991, “Generalized Q Models for Investment”, Review of Economics and Statistics, 73, 383-392.

Gilchrist, S. and Himmelberg, C.P., 1998, “Investment: Fundamentals and Finance”, in B.S. Bernanke and J. Rotemberg (Eds.), NBER Macroeconomics Annual, Cambridge, MA: MIT Press, 223-261.

Hamermesh, D.S., 1989, “Labour Demand and the Structure of Adjustment Costs”, American Economic Review, 79, 674-689.

Hamermesh, D.S., 1993, “Labour Demand” Princeton University Press, Princeton, New Jersey.

Hu, X. and Schiantarelli, F., 1998, "Investment and Capital Market Imperfections: A Switching Regression Approach Using US Firm Level Data”, Review of Economics and Statistics, 80, 466-479.

Letterie, W.A., and Pfann, G.A., 2007, “Structural Identification of High and Low investment Regimes” Journal of Monetary Economics, 54, 797-819

Letterie, W.A., Pfann, G.A., and Polder, J.M., 2004, "Factor Adjustment Spikes and Interrelation: An Empirical Investigation”, Economics Letters, 85, 145-150.

Merz, M., and Yashiv, E., 2007, "Labour and the Value of the Firm”, American Economic Review, 97, 1419-1431.

Mundlak, Y., 1978, “On the Pooling of Time Series and Cross Section Data”, Econometrica, 46, 69-85.

Nadiri, M.I., and Rosen, S., 1969, “Interrelated Factor Demand Functions”, American Economic Review, 59, 457-471.

Nilsen, Ø.A, and Schiantarelli, F., 2003, “Zeroes and Lumps in Investment: Empirical Evidence on Irreversibilities and Non Convexities” Review of Economics \& Statistics, 2003, 85, 1021-1037 
Nilsen, Ø.A, Raknerud, A., Rybalka, M. and Skjerpen, T., 2009, “Lumpy Investments, Factor Adjustments and Labour Productivity”, Oxford Economic Papers, 61, 104-127.

Nilsen, Ø.A, Salvanes, K.G. and Schiantarelli, F., 2007, "Employment Changes, The Structure of Adjustment Costs, and Plant Size” European Economic Review, 51, 577598.

Pfann, G.A. and Verspagen, B., 1989, “The Structure of Adjustment Costs for Labour in the Dutch Manufacturing Sector”, Economics Letters, 29, 365-371.

Rota, P., 2004, "Estimating Labour Demand with Fixed Costs”, International Economic Review, 45, 25-48.

Sakellaris, P., 2004, "Patterns of Plant Adjustment”, Journal of Monetary Economics, 51, 425-450.

Shapiro, M., 1986, “The Dynamics of Demand for Capital and Labour", Quarterly Journal of Economics, 51, 513-542. 


\section{Appendix:}

Derivation shadow values $\lambda_{t}^{K}$ and $\lambda_{t}^{L}$ :

The terms $\lambda_{t}^{K}$ and $\lambda_{t}^{L}$ represent the Lagrange multipliers for capital and labour respectively, associated with constraints given by equation (3). Using equation (1), the Lagrangean for this optimization problem is:

$$
\mathcal{L}_{t}=V_{t}+\sum_{s=0}^{\infty} E_{t}\left[\lambda_{t}^{K}\left(I_{t}+\left(1-\delta_{K}\right) K_{t}-K_{t+1}\right)+\lambda_{t}^{L}\left(I_{t}+\left(1-\delta_{L}\right) L_{t}-L_{t+1}\right)\right]
$$

To obtain the Lagrange multiplier for capital one can solve

$$
\frac{\partial \mathcal{L}_{t}}{\partial K_{t+1}}=-\lambda_{t}^{K}+\frac{\partial E_{t}\left(\beta\left(F\left(A_{t+1}, K_{t+1}, L_{t+1}\right)-w_{t+1} L_{t+1}-C\left(I_{t+1}, K_{t+1}, H_{t+1}, L_{t+1}\right)\right)\right)}{\partial K_{t+1}}+E_{t}\left(\left(1-\delta_{K}\right) \lambda_{t+1}^{K}\right)=0
$$

Note that the operator $E_{t}$ denotes that expectations are taken with respect to information available at time $t$ and that $A_{t}$ is a stochastic variable capturing randomness in technology or demand conditions faced by the firm. In the above expression, the expected marginal adjustment cost appears. The value of the marginal adjustment cost is contingent on the next period decisions concerning labour and capital. To account for this, in the next, $P$ refers to a probability of an event occurring. For this probability, the superscript $K$ refers to the event of only capital adjustment, $L$ refers to only labour adjustment, $B$ refers to adjustment of both labour and capital. Hence,

$$
\lambda_{t}^{K}=E_{t} \sum_{s=0}^{\infty}\left(1-\delta^{K}\right)^{s} \beta^{s+1}\left[\begin{array}{l}
\frac{\partial\left(F\left(A_{t+s+1}, K_{t+s+1}, L_{t+s+1}\right)\right)}{\partial K_{t+s+1}}-\frac{\partial\left(P_{t+s+1}^{K} C\left(I_{t+1}, K_{t+1}, H_{t+1}, L_{t+1}\right)\right)}{\partial K_{t+s+1}} \\
-\frac{\partial\left(P_{t+s+1}^{L} C\left(I_{t+1}, K_{t+1}, H_{t+1}, L_{t+1}\right)\right)}{\partial K_{t+s+1}}-\frac{\partial\left(P_{t+s+1}^{B} C\left(I_{t+1}, K_{t+1}, H_{t+1}, L_{t+1}\right)\right)}{\partial K_{t+s+1}}
\end{array}\right]
$$

Similarly it is possible to show 


$$
\lambda_{t}^{L}=E_{t} \sum_{s=0}^{\infty}\left(1-\delta^{L}\right)^{s} \beta^{s+1}\left[\begin{array}{l}
\frac{\partial\left(F\left(A_{t+s+1}, K_{t+s+1}, L_{t+s+1},\right)\right)}{\partial L_{t+s+1}}-w_{t+s+1}-\frac{\partial\left(P_{t+s+1}^{K} C\left(I_{t+1}, K_{t+1}, H_{t+1}, L_{t+1}\right)\right)}{\partial L_{t+s+1}} \\
-\frac{\partial\left(P_{t+s+1}^{L} C\left(I_{t+1}, K_{t+1}, H_{t+1}, L_{t+1}\right)\right)}{\partial L_{t+s+1}}-\frac{\partial\left(P_{t+s+1}^{B} C\left(I_{t+1}, K_{t+1}, H_{t+1}, L_{t+1}\right)\right)}{\partial L_{t+s+1}}
\end{array}\right]
$$

These expressions reflect that current factor demand affects the production scale and hence productivity of next periods and it determines the size of the adjustment costs and the probability of adjustment.

\section{Real replacement value of the capital stock at the beginning of period $t\left(K_{t}\right)$ :}

The replacement value is computed using the perpetual inventory method. This method requires a starting value for the capital stock. The data do not provide information on insurance or book value of the capital stock. Therefore the starting value is estimated as follows. The real stock of capital at the beginning of year $m=t 0+n$, where $n$ is an integer larger than or equal to 1 and where $t 0$ is the period of observing the initial stock of capital, is given by

$$
K_{m}=I_{m-1}+(1-\delta) I_{m-2}+\ldots+(1-\delta)^{n-1} I_{t 0}+(1-\delta)^{n} K_{t 0}
$$

where $\delta$ is the rate of depreciation set equal to 0.06 . If it is assumed that in year $t$ the firm grows at a rate equal to $g_{t}$ then investment in the $n$ periods should be approximately sufficient to ensure that

$K_{m}=\left(1+g_{m-1}\right) \ldots\left(1+g_{t 0}\right) K_{t 0}$.

Given the values $g_{t}$ it is possible to solve for the value of $K_{t 0} . g_{t}$ is approximated by calculating the firm's real production growth from time $t-1$ to $t$. The value of $n$ is set equal to 5. The reason is that a sufficiently long period is required to estimate the starting value of capital, because firms tend to concentrate investment in a relatively short period of time. If $n$ is very small the probability of underestimating the starting value of the capital would be 
considerable. This procedure requires an uninterrupted sequence of data on production and investment during at least five years. As the data start in 1993 and run until 2005, the starting year for the data needed to construct the capital stock for a plant can vary between 1993 and 2000. Observations for which a negative stock of capital is found are dropped as these are poorly estimated. Given the initial value of the replacement value of the capital stock at the beginning of year $t$ is calculated using the perpetual inventory formula $K_{t}=I_{t-1}+(1-\delta) K_{t-1}$.

\section{Simulation exercise:}

Starting point for the simulation is given by equations $5,8,11$, and 14 . These equations reveal what drives the adjustment decisions made by firms in the simulation. Other input to the simulation is given by the estimates depicted in Table 4 . These provide a number of restrictions to the simulation routine: $\alpha^{L} / \alpha^{K}=0.0002, \quad \alpha^{K L} / \alpha^{L}=-0.3029$ and $\left(b^{L} / b^{K}\right) /\left(\sigma^{K} / \sigma^{L}\right)^{2}=10.16$. Also the coefficients of the variables determining the shadow values of capital and labour are used to fix the parameters in equation 14 . To find a parameter combination that gives the best possible fit to the observed data, an optimization routine is run, each time simulating a different panel of firm behaviour. The parameters to be determined are levels of $\alpha^{K}$ and $b^{L}$, while the remaining cost parameters and the ratio of $\sigma^{K} / \sigma^{L}$ are determined by the restrictions above. The parameter $b^{K}$ is set equal to 1 as a normalization because the procedure can only identify a local optimum that is unique up to a scaling factor. To evaluate the fit of each simulation, the sum of squared relative deviations from a vector of empirical moments is considered. These include first and second moments of adjustment rates in addition to separate and joint inaction shares. For each iteration, the simulation of optimal firm behaviour is run to create a panel of 10000 observations consisting of 1250 firms which operate during a period of 8 years. Initial levels of capital, labour and production are randomly drawn from lognormal distributions with means and standard 
deviations chosen to replicate the properties of the empirical sample. Also, wages and productivity shocks are drawn for each period in which the firms operate. In each period, marginal values are computed based on the production and input levels, wages and productivity shocks. In accordance with the theoretical model, optimal adjustment decisions are then made based on shadow values and the adjustment costs faced by each firm. After that, input levels for next period are determined by adding any adjustments to the existing stocks. At the end of year 8 , the behaviour is summarized in a vector of key moments and compared to the empirical data, after which the routine moves on to the next iteration. Table A1 shows a comparison of moments after the final simulation.

[Insert Table A1 about here] 
Figure 1: Investment Regimes, $\alpha^{K L}>0$

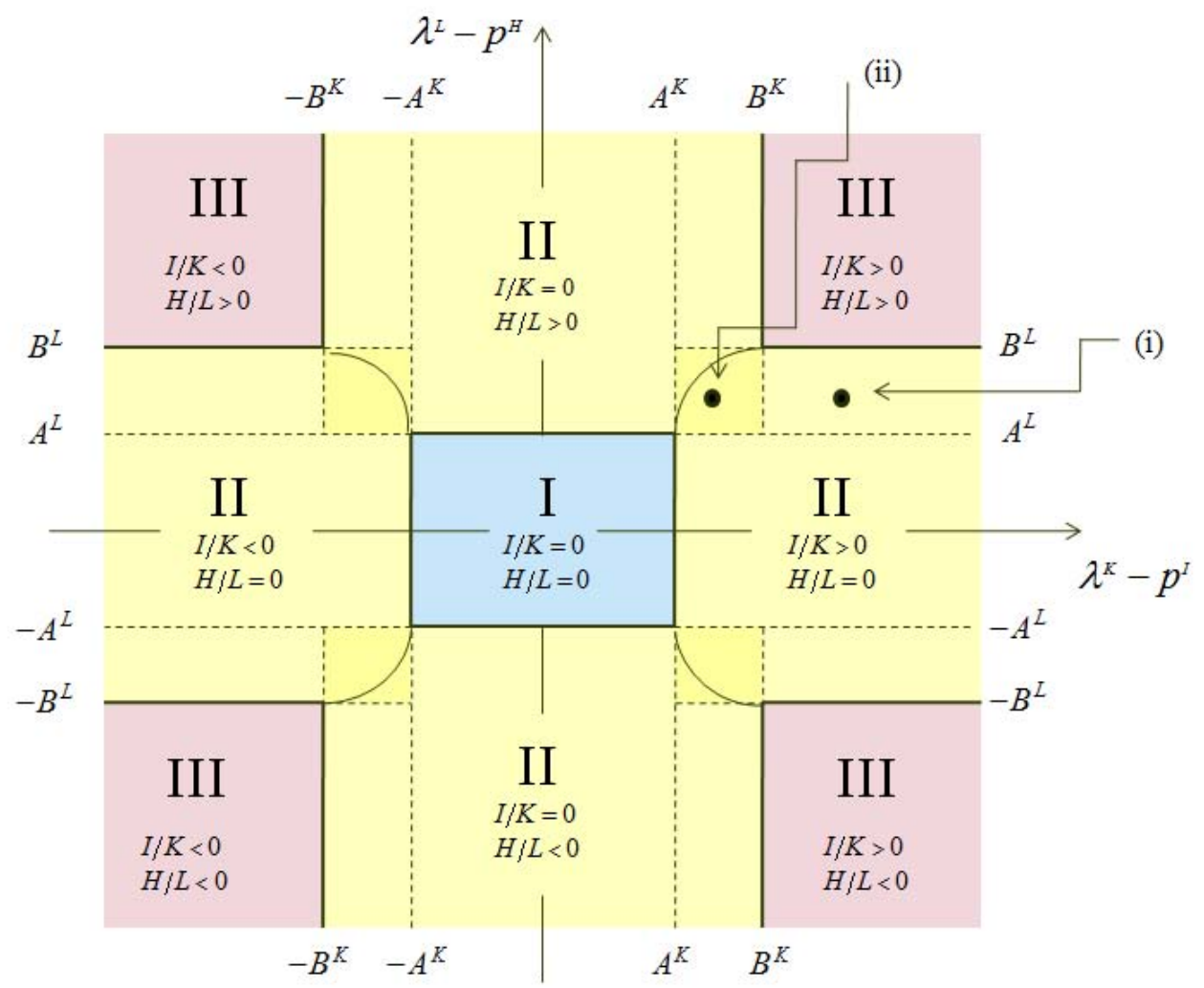


Figure 2: Investment Regimes, $\alpha^{K L}<0$

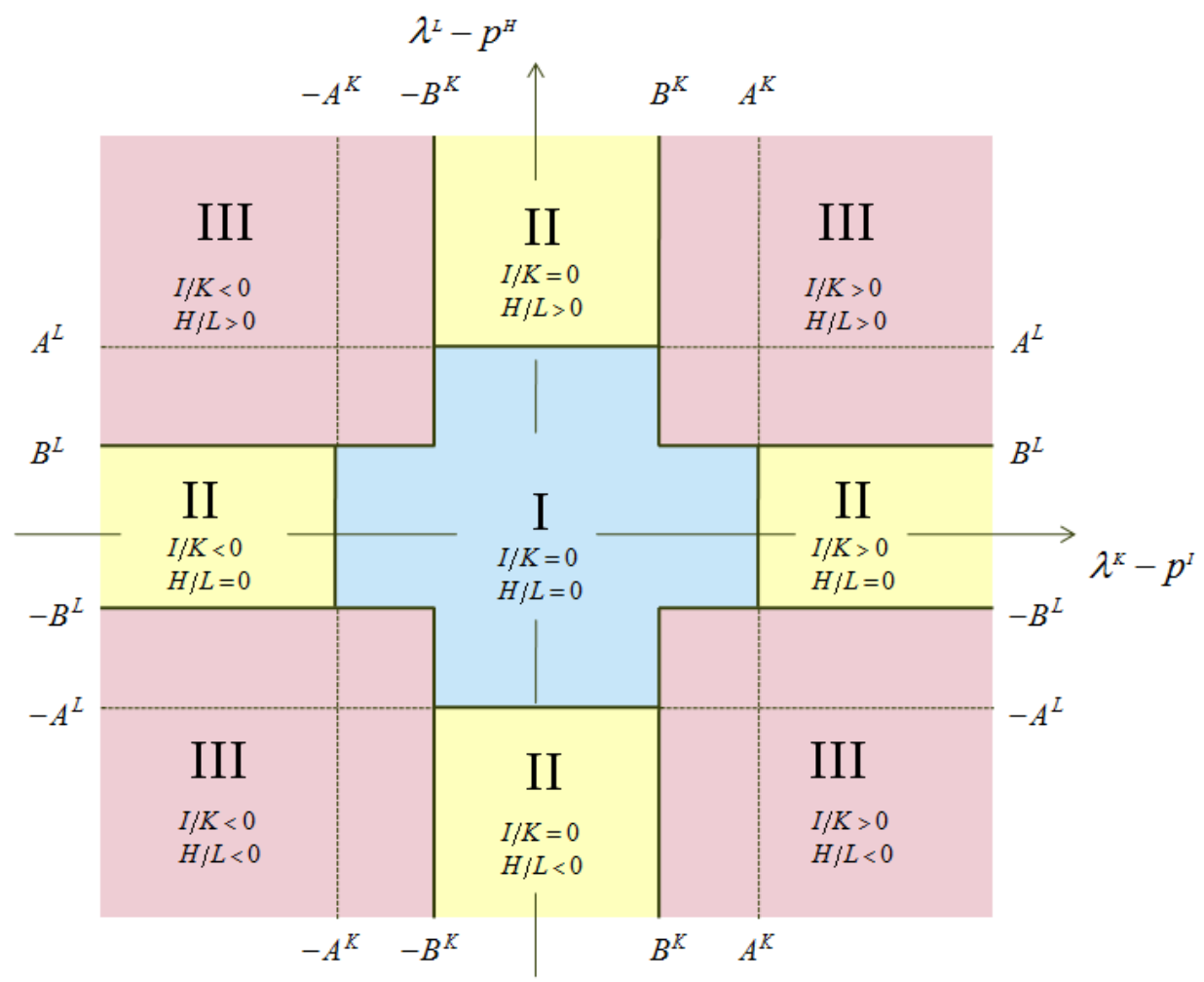


Figure 3: Capital

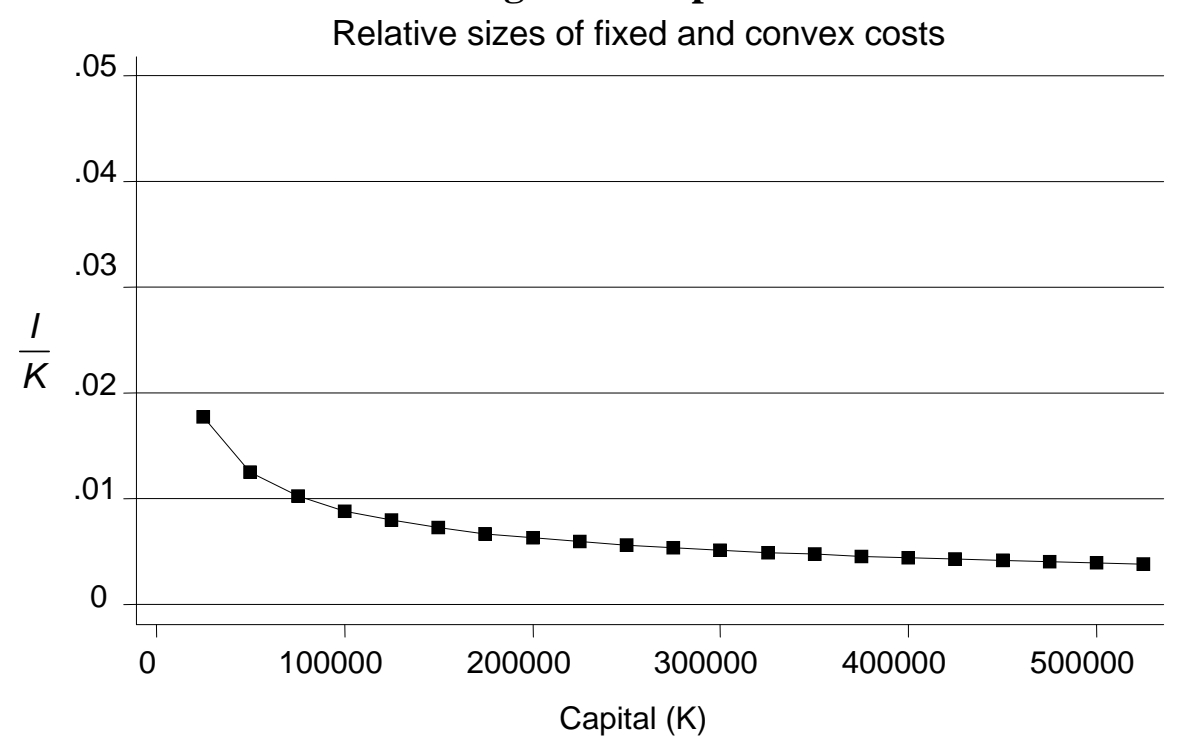

Note: The line in the figure represents combinations of adjustment rates and existing levels of capital at which the convex cost component is exactly equal to the fixed cost component incurred by an adjustment in capital. The area above the curve represents combinations where the convex component is largest. 


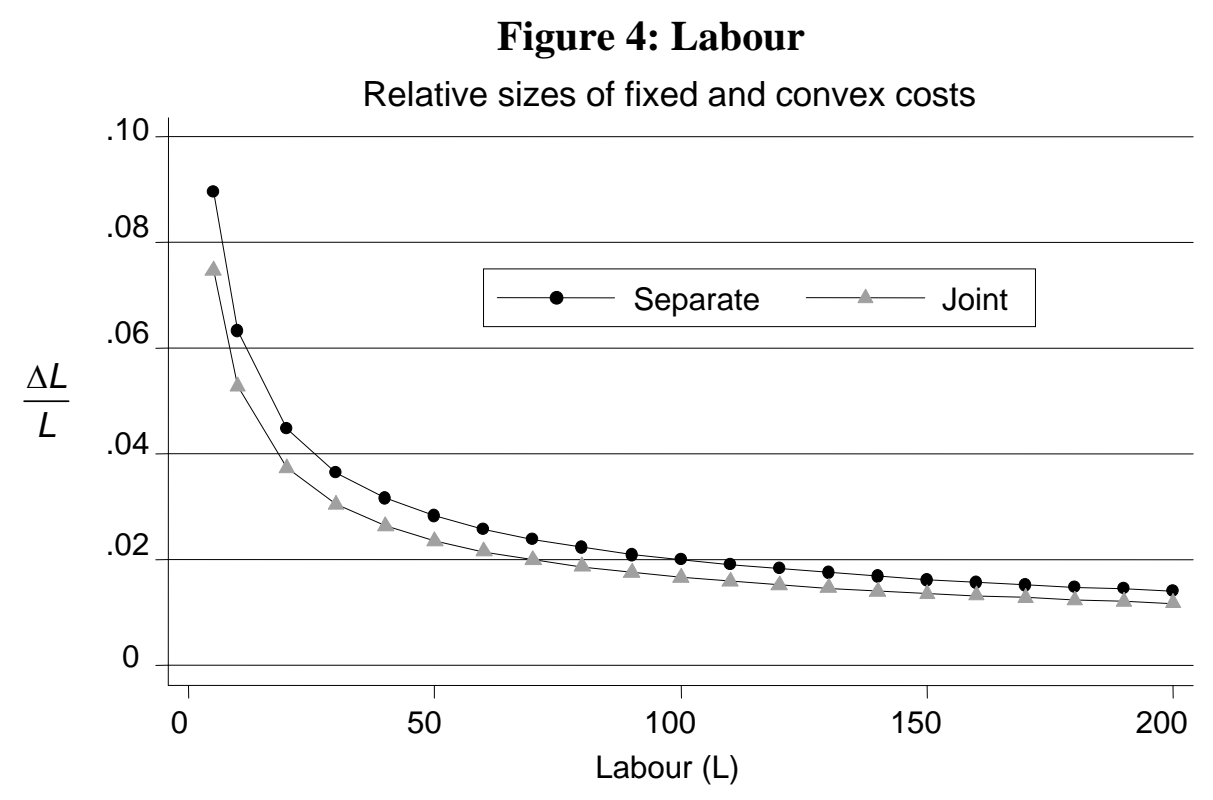

Note: The lines in the figure represent combinations of adjustment rates and existing levels of labour at which the convex cost component is exactly equal to the fixed cost component incurred by an adjustment of labour. The areas above the curves represent combinations where the convex component is largest. The line with dots represents instances where the firm only conducts labour adjustment. The line with triangles depicts instances where both labour and capital are adjusted. 
Table 1: Descriptive statistics

\begin{tabular}{|c|c|c|c|c|c|c|c|c|c|}
\hline & \multirow[t]{2}{*}{ Mean } & \multirow{2}{*}{$\overline{\text { St.dev }}$} & \multicolumn{2}{|l|}{ Correlations } & \multirow[b]{2}{*}{$(\mathrm{Y} / \mathrm{K})_{-1}$} & \multirow[b]{2}{*}{$(\mathrm{Y} / \mathrm{L})_{-1}$} & \multirow[b]{2}{*}{$W_{-1}$} & \multirow[b]{2}{*}{ K } & \multirow[b]{2}{*}{ L } \\
\hline & & & $\mathrm{I} / \mathrm{K}$ & $H / L$ & & & & & \\
\hline $\mathrm{I} / \mathrm{K}$ & 0.134 & 0.251 & 1.000 & & & & & & \\
\hline$H / L$ & 0.004 & 0.175 & 0.116 & 1.000 & & & & & \\
\hline$(\mathrm{Y} / \mathrm{K})_{-1}$ & 7.389 & 8.646 & 0.263 & 0.061 & 1.000 & & & & \\
\hline$(\mathrm{Y} / \mathrm{L})_{-1}$ & 1362.2 & 1453.3 & 0.002 & 0.067 & 0.179 & 1.000 & & & \\
\hline$W_{-1}$ & 294.6 & 82.6 & -0.028 & 0.106 & 0.031 & 0.341 & 1.000 & & \\
\hline K & 59127.5 & 436941.0 & -0.039 & -0.011 & -0.079 & 0.107 & 0.075 & 1.000 & \\
\hline L & 75.5 & 130.0 & 0.006 & 0.030 & -0.042 & 0.129 & 0.159 & 0.216 & 1.000 \\
\hline
\end{tabular}

Notes: Wages, $w$, are defined as total wage expenditure per employee, including pay-roll taxes

Capital, $K$, is given in 1000 NOK $(\approx € 125)$ in 1996 prices 
Table 2: Distribution of $I / K$ and H/L

\begin{tabular}{|c|c|c|c|c|c|c|}
\hline $\mathrm{I} / \mathrm{K}$ & $\begin{array}{l}\mathbf{H} / \mathbf{L} \\
<-0.667,-0.167]\end{array}$ & $<-0.167,0.000>$ & $=0$ & \multicolumn{2}{|c|}{$<0.000,0.167]<0.167,+>$} & \multirow[b]{2}{*}{0.7} \\
\hline$<-0.667,-0.167]$ & 0.2 & 0.2 & 0.1 & 0.1 & 0.1 & \\
\hline$<-0.167,0.000>$ & 0.8 & 1.5 & 0.5 & 0.8 & 0.2 & 3.8 \\
\hline$=0$ & 1.6 & 3.9 & 2.2 & 2.4 & 1.0 & 11.2 \\
\hline$<0.000,0.167]$ & 5.0 & 23.3 & 9.0 & 19.6 & 4.6 & 61.6 \\
\hline \multirow[t]{2}{*}{$<0.167,+>$} & 1.2 & 6.6 & 3.3 & 8.4 & 3.3 & 22.9 \\
\hline & 8.8 & 35.5 & 15.1 & 31.3 & 9.3 & 100.0 \\
\hline
\end{tabular}


Table 3: Correlation in timing

\begin{tabular}{|c|c|c|c|c|c|}
\hline$(1 / K)_{+1}$ & $\mathrm{I} / \mathrm{K}$ & $(\mathrm{I} / \mathrm{K})_{-1}$ & $(\mathrm{H} / \mathrm{L})_{+1}$ & $\mathrm{H} / \mathrm{L}$ & $(\mathrm{H} / \mathrm{L})_{-1}$ \\
\hline 1.000 & & & & & \\
\hline 0.131 & 1.000 & & & & \\
\hline 0.071 & 0.148 & 1.000 & & & \\
\hline 0.108 & 0.070 & 0.036 & 1.000 & & \\
\hline 0.080 & 0.116 & 0.083 & -0.083 & 1.000 & \\
\hline 0.043 & 0.090 & 0.117 & 0.004 & -0.078 & 1.000 \\
\hline
\end{tabular}


Table 4: Estimation Results - Two Factor Demand Model

\begin{tabular}{ccc}
\hline & Capital Adjustment & Labour Adjustment \\
$(\mathrm{Y} / \mathrm{K})_{-1}$ & 0.00695 & 0.00476 \\
& $(0.00184)$ & $(0.00126)$ \\
$(\mathrm{Y} / \mathrm{L})_{-1}$ & 0.0000077 & -0.0000166 \\
& $(0.0000128)$ & $(0.0000077)$ \\
$\mathrm{W}_{-1}$ & 0.000361 & 0.00195 \\
& $(0.000193)$ & $(0.00015)$ \\
\hline
\end{tabular}

\begin{tabular}{cc}
\hline Pseudo Threshold Estimates & 359.7 \\
$A^{K}$ & $(19.4)$ \\
$A^{L}$ & 0.734 \\
& $(0.084)$ \\
$B^{K}$ & 359.7 \\
& $(19.4)$ \\
$B^{L}$ & 0.511 \\
Parameter Ratios & $(0.085)$ \\
$\frac{\alpha^{L}}{\alpha^{K}}$ & 0.0002 \\
$\frac{\alpha^{K L}}{\alpha^{K}}$ & $(0.0023)$ \\
$\frac{\alpha^{K L}}{\alpha^{L}}$ & -0.0001 \\
$\frac{b_{L}}{b_{K}} \cdot \frac{\left(\sigma_{\varepsilon}^{K}\right)^{2}}{\left(\sigma_{\varepsilon}^{L}\right)^{2}}$ & $(0.000004)$ \\
\hline
\end{tabular}

Other Parameter

\begin{tabular}{cc}
$\rho_{\varepsilon}$ & 0.154 \\
$N$ & $(0.015)$ \\
\hline$N$ & 13511 \\
\hline
\end{tabular}

Note: Standard errors are in parentheses. A constant term, year and sector dummies are included in the estimation but not reported here to conserve space. 
Table 5: Estimation Results - Two Factor Demand Model with Mundlak Variables

\begin{tabular}{ccc}
\hline & Capital Adjustment & Labour Adjustment \\
$(\mathrm{Y} / \mathrm{K})_{-1}$ & 0.00385 & 0.00270 \\
& $(0.00269)$ & $(0.00202)$ \\
$(\mathrm{Y} / \mathrm{L})_{-1}$ & 0.0000257 & 0.0000126 \\
& $(0.0000211)$ & $(0.0000126)$ \\
$\mathrm{W}_{-1}$ & 0.000267 & 0.00331 \\
& $(0.000260)$ & $(0.00022)$ \\
\hline
\end{tabular}

\section{Pseudo Threshold Estimates}

$A^{K}$

360.8

(19.6)

$A^{L}$

0.745

$(0.085)$

$B^{K}$

360.8

(19.6)

$B^{L}$

0.519

(0.151)

\section{Parameter Ratios}

$\frac{\alpha^{L}}{\alpha^{K}}$

0.0002

$\frac{\alpha^{K L}}{\alpha^{K}}$

$\frac{\alpha^{K L}}{\alpha^{L}}$

$-0.00006$

$(0.00003)$

$\frac{b_{L}}{b_{K}} \cdot \frac{\left(\sigma_{\varepsilon}^{K}\right)^{2}}{\left(\sigma_{\varepsilon}^{L}\right)^{2}}$

\section{Other Parameter}

\begin{tabular}{cc}
$\rho_{\varepsilon}$ & 0.155 \\
$N$ & $(0.015)$ \\
\hline$N$ & 13511 \\
\hline
\end{tabular}

Note: Standard errors are in parentheses. A constant term, year dummies, sector dummies and presample averages of $Y / K, Y / L$ and $w$ are included in the estimation but not reported here to conserve space. 
Table 6: Estimation Results - Single Factor Demand Equations

\begin{tabular}{ccc}
\hline & Capital Adjustment & Labour Adjustment \\
\hline$(\mathrm{Y} / \mathrm{K})_{-1}$ & 0.00692 & 0.00481 \\
& $(0.00185)$ & $(0.00126)$ \\
$(\mathrm{Y} / \mathrm{L})_{-1}$ & 0.000008 & -0.000017 \\
& $(0.000013)$ & $(0.000008)$ \\
$\mathrm{W}_{-1}$ & 0.000368 & 0.00195 \\
& $(0.000195)$ & $(0.00015)$ \\
\hline
\end{tabular}

\section{Pseudo Threshold Estimates}

$\begin{array}{ll}A^{K} & 357.1 \\ & (19.2)\end{array}$

\begin{tabular}{|c|c|c|}
\hline$A^{L}$ & & $\begin{array}{c}0.537 \\
(0.024) \\
\end{array}$ \\
\hline$N$ & 13511 & 13511 \\
\hline
\end{tabular}

Note: Standard errors are in parentheses. A constant term, year and sector dummies are included in the estimation but not reported here to conserve space. 
Table A1: Simulation Overview

\begin{tabular}{ccc}
\hline Parameter inputs & Simulation & Data \\
\hline$\alpha^{L} / \alpha^{K}$ & 0.0002 & 0.0002 \\
$\alpha^{K L} / \alpha^{L}$ & -0.3029 & -0.3029 \\
$\left(b^{L} / b^{K}\right) \cdot\left(\sigma^{K} / \sigma^{L}\right)^{2}$ & 10.16 & 10.16 \\
$\left(b^{L} / b^{K}\right)$ & 0.290 & - \\
$\left(\sigma^{K} / \sigma^{L}\right)^{2}$ & 35.00 & - \\
$b^{L}$ & 1.00 & - \\
$b^{K}$ & 3.444 & - \\
$\alpha^{K}$ & 13.66 & - \\
$\alpha^{L}$ & 0.0201 & - \\
$\alpha^{K L}$ & -0.0061 & - \\
$\sigma^{K}$ & 0.8435 & - \\
$\sigma^{L}$ & 0.1426 & - \\
\hline
\end{tabular}

\section{Data moments}

\begin{tabular}{ccc}
\hline frequency $\mathrm{I} / \mathrm{K}=0$ & 0.108 & 0.108 \\
frequency $\mathrm{H} / \mathrm{L}=0$ & 0.145 & 0.131 \\
frequency $\mathrm{I} / \mathrm{K}=\mathrm{H} / \mathrm{L}=0$ & 0.000 & 0.019 \\
mean(I/K) & 0.121 & 0.123 \\
$\operatorname{mean}(\mathrm{H} / \mathrm{L})$ & -0.009 & -0.009 \\
$\mathrm{sd}(\mathrm{I} / \mathrm{K})$ & 0.235 & 0.228 \\
$\mathrm{sd}(\mathrm{H} / \mathrm{L})$ & 0.143 & 0.143 \\
\hline$N$ & 10000 & 13511 \\
\hline
\end{tabular}

Note: A “-” indicates that the corresponding value is not available for the original data. 